(c) Journal of Applied Mathematics \& Decision Sciences, 2(1), 23-50 (1998)

Reprints Available directly from the Editor. Printed in New Zealand.

\title{
A DECISION SUPPORT SYSTEM FOR REGIONAL HAZARDOUS WASTE MANAGEMENT ALTERNATIVES
}

\author{
MAHYAR A. AMOUZEGAR \\ m.amouzegar@massey.ac.nz \\ Institute of Technology \& Engineering, SST 4.29, Massey University, New Zealand. \\ STEPHEN E. JACOBSEN \\ jacobsen@ee.ucla.edu \\ Department of Electrical Engineering, University of California, Los Angeles, CA 90024, USA.
}

\begin{abstract}
With the passage of the Resource Conservation and Recovery Act (RCRA), and the subsequent amendments to RCRA, efforts to provide tighter controls on the transportation and disposal of hazardous waste have been steadily gaining ground. This paper, intended as a decision support tool for regional planning, incorporates information on the hazardous waste generation, treatment capacity and the costs of waste treatment alternatives into an optimization problem of finding the relationship between governing agency and the toxic waste producing firms. As an example, we consider the problem of regional hazardous waste in the San Francisco Bay Area in Northern California.
\end{abstract}

Keywords: Decision Support System, Hazardous Waste Management, Mathematical Programming, Bilevel Programming.

\section{Introduction}

Pollution has been an inevitable accompaniment to economic activities, and as such, most societies have set goals to eliminate, or at least reduce, pollution. It has long been recognized that industries or firms may not voluntarily reduce pollution levels in the absence of any government compulsory intervention. Such intervention can take either of two forms: $a$ ) the government can takeover and run some lines of activity, or $b$ ) it can leave the activity to private initiative but regulate it.

Many states generate large amount of hazardous waste for which there is not, at present, adequate treatment and disposal capacity within the state. Federal and state legislation requires that management policies provide for adequate long-term treatment and disposal capacity for such waste. California's policy, for example, calls for meeting treatment requirements by reducing the generation of hazardous waste, with expansion of treatment and disposal capacity only as a secondary solution. Within the state, hazardous waste management planning is also being done at the regional level. Regional governments must project hazardous waste generation and plan for adequate treatment and disposal capacity in their region. Estimates of future waste generation are based on population and economic projections, and then reduced by some percentage across-the-board to account for projected waste reduction. 
At present, regional planners do not consider the relationship between treatment capacity, treatment prices and hazardous waste generation. Large off-site treatment facilities offer economies-of-scale provided that the are fully utilized; however, if the capacity is larger than anticipated demand then the facility could be forced to increase the unit treatment price which could produce further decrease in demand and price increases. As a result the facility many be be able to recover costs or operate only at higher than projected unit prices. The addition of treatment capacity could also produce other unintended outcomes: low treatment prices could undermine waste minimization efforts; or the facility may utilize excess capacity by treating wastes from outside the region.

In order to fully understand the fundamental characteristic of hazardous waste management, we must introduce two important agents in the economy: The central authority and the firms. The central authority (CA) is defined as any agent in the economy which has the authority to regulate the other agents' activity.

We define a firm as any organization that, through its activity produces some goods, not necessarily identical, in order to maximize its own profit. As a by product of the firm's activity, hazardous waste is also generated which needs to be managed.

In this paper, we present an optimization model for hazardous waste capacity planning and treatment facility location. The behavior of private firms is modeled to assess the effect of central planning decisions and price signals on hazardous waste generation and demand for treatment and disposal. In short, we are mainly concerned with the interaction between the two agents: the CA seeking to regulate the firms in order to maximize the social welfare and the firms responding to these regulations. Furthermore, we have focused our attention on a group of wastes classified as incinerable hazardous wastes since it constitute the largest non-nuclear waste group in the US.

The management of incinerable wastes are divided into four major categories:

1. Source reduction: The elimination or reduction of waste at the source.

2. Recycling: The recycling or reuse of waste material both on-site and off-site (regional level). Recycling is not $100 \%$, and some residuals need to be sent for incineration and disposal.

3. Incineration: Thermal destruction of waste at off-site facilities.

4. Disposal: Releasing material into air, water and land. This option is assumed to be a joint process with the incineration.

Among all the technique of waste management, source reduction is favored due to its lower risk to the environment, and thus is the common sense solution to the prevention of future hazardous waste problems. But due to lack of proper environmental regulation and/or economic consideration, recycling and incineration are part of today's waste management options. The latter processes bring with them 
certain damage (or externalities) to the environment which we will call pollution damage.

The model, intended as a decision support tool for a regional hazardous waste management authority, is necessarily a simplification of the actual conditions and subject to constraints and assumptions which are described below. Still, it provides a framework for qualitatively comparing the effects of different planning options.

\section{Scope of Hazardous Waste Problem}

More than 60,000 chemicals (excluding pharmaceuticals or pesticides) enter into many products and services that shape today's lifestyle. Taken together, these chemicals, comprise a huge industry - in the United States alone, sales during 1995 were over $\$ 200$ billion. The sheer variety, ubiquity and economic importance of chemicals means that effective regulation to safeguard against undesirable health or environmental side effects is quite challenging[31]. In California, every year, about 26,000 firms generate and ship off-site over 2.2 million tons of hazardous wastemore than 150 pounds per person in the state. This represents an increase of over 600,000 tons from the total reported just two years earlier. The rapid production of hazardous waste combined with increase in disposal cost and decrease in the available numbers of landfill sites, changes in legislation, and more public awareness have dramatically altered the way in which we can deal with hazardous waste. Prior to the late 1980's, a detailed accounting of the generation and disposal patterns for hazardous waste streams was unavailable; however, with the data collection provisions enacted under Superfund reauthorization and the Resource conservation and Recovery Act (RCRA), the legal authority to collect such data was put in place. Now there are several data bases which provide partial pictures of hazardous waste generation and disposal. The Toxic Release Inventory (TRI)[41], collected annually under Superfund Amendment and Reauthorization Act (SARA), Title III, provides data on the emission profiles of more than 300 chemical species. While the TRI data are useful for profiling waste generation patterns, they provide little information on disposal methods. In contrast, the biennial survey of generators and the biennial survey of Treatment, Storage and Disposal facilities collected under RCRA, provide data on disposal patterns but little data beyond waste category on the composition of the waste streams.

In 1985, Environmental Protection Agency (EPA) conducted the National Screening Survey of Hazardous Waste Treatment, Storage, Disposal and Recycling (TSD) facilities. The survey was designed to estimate the total quantity of hazardous waste managed by TSD facilities and to identify hazardous waste management processes. This survey identified 2,959 facilities, regulated under RCRA, which managed a total of 247 million tons of waste [43]. An additional 322 million tons of hazardous waste was handled by units exempt from RCRA reporting requirements. 


\subsection{Evolution of State and Federal Regulation}

Currently there are 11 major environmental laws for controlling different types of waste generated throughout the country [42]. One of these laws which concerns hazardous waste, is the Resource Conservation and Recovery Act of 1976 with its "cradle-to-grave" provisions for controlling the storage, transportation, treatment and disposal of hazardous waste. RCRA was significantly amended in 1980 and 1984. The 1984 amendment of RCRA, called Hazardous and Solid Waste Act (HSWA) is very important in establishing more stringent standards in waste management strategy. These amendments have restricted untreated hazardous waste from land disposal ("Land Ban")[40] and state laws such as Hazardous Waste Management Act of 1986 (SB1500), which augments the federal Land Ban to include some California-only hazardous wastes. The Land Ban also specifies hazardous waste treatment standards, which for many wastes require that specific treatment technologies be applied. California law further requires that all hazardous waste containing more than one percent volatile organic compounds or having a heating value of more than 3,000 BTU/lb must either be incinerated or treated by an equally effective approved process [36].

Planning for hazardous waste treatment and disposal is being done at both the state and county level. Federal law (CERCLA $\S 104(\mathrm{c})(9))$ requires that states, or a cooperating association of states, prepare Capacity Assurance Plans (CAP) or lose federal funding for Superfund cleanups in the state. Where there is a shortfall of treatment and disposal capacity, the state(s) must show that measures are being taken to meet the shortfall. In California, AB650 has required that the Department of Toxic Substances Control prepare such a plan in 1989 and revise it every three years.

Long before the state's first Capacity Assurance Plan was prepared, the legislature had recognized that additional facilities were needed, but that siting of such facilities was meeting strong opposition at the local level. 'Hazardous Waste: Management Plans and Facility Siting Law'[37], known as Tanner Act, provided guidelines and funding for county and regional governments to assess hazardous waste generation within their jurisdiction and to develop waste management plans to guide future policy decisions, including the siting of new treatment facilities. The law also set up a process for evaluating facility siting proposals through a Local Assessment Committee and a state appeals board.

The legislation allows counties to participate in regional associations for hazardous waste management planning. The two principle association are the Association of Bay Area Governments (ABAG), comprised of Alameda, Contra Costa, Marin, Napa, San Francisco, San Mateo, Santa Clara, Solano and Sonoma counties, and the Southern California Hazardous Waste Management Authority (SCHWMA), comprised of Imperial, Los Angeles, Orange, Riverside, San Bernardino, San Diego and Santa Barbara counties. ABAG and SCHWMA account for approximately $25 \%$ and $50 \%$, respectively, of all hazardous waste generation in the state. 


\section{A Survey of Pollution Control}

A major tenet of this paper is that there are significant gaps in our understanding of pollution control and firms' behavior in other than highly abstract economies with full information assumptions. It is important to recognize our limited knowledge about the firms' response to regulatory action by the central authority; and even more significantly, the lack of complete data on hazardous waste generation and treatment.

In this section, we review past work that can contribute to a better understanding of subsequent sections. Roughly speaking, the literature includes four broad, and sometimes overlapping, topical areas: conceptual models, extensions to the earlier models, effect of uncertainty and optimization methods.

\subsection{Conceptual Models}

Conceptual models and discussions focusing on efficiency gains of market-base approaches compared with command and control has been discussed by many authors such as Kneese[22], Dale[8], Baumol and Oats[4], and Kneese and Schultz[23]. Allen Kneese[22] had the early insights in terms of treating pollution management as an economic allocation processes in his work on water pollution. His contribution was to point out that pollution control is not just an engineering problem (which can be solved by technology), or just a political problem, but it is also an economic allocation problem. His prescription was to utilize pigouvian fee (i.e., emission charge), to achieve a socially desirable level of pollution.

Following Kneese's work on water pollution, Crocker[7] examined air pollution control as an economic allocation problem. Although his work treats the problem on a very general level, he does introduce the notion of marketable property right for the use of air resources. Dale[8] expands considerably on the notion of a pollution permit and property rights.

Although these early works introduced most of the ideas used by today's researchers, it is noticeably deficient in the quantitative rigor needed to approach pollution problems.

\subsection{Extensions}

Extensions of these models addressing complications such as space (i.e., multiple regions) and fluctuating pollutant disposal. Montgomery[32] and Tietenberg[39] have developed general equilibrium model to examine optimal pollution control focusing on these considerations. Montgomery[32] examines marketable permits to pollute within a spatial economy. His paper is important because it shows that an equilibrium will exist for a marketable permit system such as proposed by Dale[8].

Susan Rose-Ackerman[34] pointed out a host of practical problems associated with emission fees. Some of her criticism have previously surfaced in terms of general 
difficulties with the marginalist allocation process. Other perceived problems with emission fees are merely observation on the difficulty of controlling pollution and are not unique to economic instrument. Therefore, her criticism do not appear to significantly weaken the case for emission fees or marketable permits, a case whose principal interest lies in its alignment of public and private incentives. RoseAckerman suggests two problems: One problems arises when non-constant return to scale apply to either pollution damage or emissions. In such case, marginal cost pricing can lead to nonzero profit for producer. A firm may be driven out of business, or forced to leave the region, if it is forced to pay the emission fee. But this can be true for any input and there is no indication that economic efficiency is reduced.

A second issue raised by her is the potential inefficiencies associated with an emission fee that is uniform in either space or time. These inefficiencies (relative to a uniform emission standard) associated with uniform fee depend on the curvature of the cost and benefit functions. But once again, it should be pointed out that fees need not to be uniform.

Finally, Kruppick, et. al. [25] examined the marketable permit system for the control of air pollution. In their paper, they allowed for free trade of emission permits subject to the constraint of no violations of the predetermined air quality standard at any receptor points.

\subsection{Effects of Uncertainty [Price vs. Quantity]}

A number of authors have introduced uncertainty into their analysis and on this basis have shown the optimality of particular control mechanism. Weitzman[45] has shown under what conditions price instrument are preferred to quantity instruments in centrally allocating production and consumption. He confirmed Lerner's conjecture([29]) that under uncertainty, the choice between fee and permits will depends on the slopes of the marginal damage and cost functions. Kolstad[24] explicitly included uncertainty in his empirical model. He examined and compare three regulatory issues: price control vs. quantity control; spatially differentiated vs. undifferentiated control; and command-and-control regulation vs. economic instrument.

Beavis and Dobbs[5] examined the firm behavior under regulatory control with the assumption of stochastic effluent generation. These authors assumed that waste discharge depends on some input and a continuous random variable with a known density function.

\subsection{Optimization Approach}

Many authors have attempted optimization techniques in the pollution abatement problem (e.g., [30], [15], [17], [14]). Graves, et. al. [15] used a large scale nonlinear programming in a pollution abatement model for West Fork White River in Indiana 
in order to minimize the total cost of pollution abatement structure subject to water quality in each section of the river. Haimes, et. al. [16] and Hass [19] approached the abatement of water pollution through decomposition techniques of Dantzig and Wolfe[9]. Their goal was to simultaneously compute an optimal waste water treatment configuration and to determine optimal pollution taxes to achieve this configuration.

Models of Haime, et. al. [16] and Hass[19] depend crucially upon the assumption that the system is i) centralized, and ii) the centralized system is capable of decentralization. Jacobsen[21] showed that once revenue sensitivities and appropriate benefit measures are introduced, usually both of the above assumptions do not hold. Hall and Jacobsen[17] highlighted the importance of response functions due to specific regulatory policies. They developed an optimization model based on consumers' surplus, profit loss, and changes in tax revenues; and concluded that, when information costs are too high, it is most efficient to tax the solid wastes directly rather than the tax the goods that produced such wastes.

In most of these models, the solution is derived from a microeconomic approach, in the sense that it is found by locating the point where the marginal treatment cost equals to the marginal damage cost from the perspective of a particular individual polluter (some noted exceptions are Jacobsen[21], Hall and Jacobsen[17], and Kolstad[24]). However, a serious shortcoming of these models is that complete information on the production and damage cost functions of each and every firm is assumed to be known. Although, each firm may know its own production cost functions, there is no reason to believe that this information will be readily available to the central authority.

Some researcher have conceptualized the problem in terms of a multilevel frame work [1], [19], [16], [24]. Although Hass[19] seemed to realize the existence of two levels, he did not formulate his model as such. Instead, he modeled the problem as a single level and solved it by using Dantzig-Wolfe nonlinear decomposition.

Haimes, et. al. [16] also recognized the need to consider the problem from a multilevel modeling viewpoint. They proposed a formulation consisting of three level: a central authority, a regional treatment plant, and the individual polluter. Their solution method decomposed the optimization problem into a set of hierarchically ordered subproblems. The solutions of these subproblems were then coordinated to obtain an optimal solution to the original problem. More specifically, once the central authority determines the tax schedule, it send this information down to the lower levels. The lower levels then process the tax structure and pass results back up to the central authority as optimal treatment levels. Using these treatment levels, the central authority checks the quality constraints to determine if the previous taxing structure is too high (no binding constraints), too low (some constraint violated), or optimal(no constraints violated, some binding constraint). If the previous tax structure is not optimal, a new tax structure is developed. The iterative nature of this solution technique is necessary since there is no mechanism, inherent in the model, which assumes that central authority has any knowledge of the lower level optimization problems. The obvious difficulty with such iterative tax setting is that 
Table 1. Hazardous Waste Generation in California

\begin{tabular}{|l|r|r|r|r|}
\hline & \multicolumn{1}{|c|}{1988} & \multicolumn{1}{|c|}{1989} & \multicolumn{1}{c|}{1990} & \multicolumn{1}{|c|}{1991} \\
\hline In-state generation, HWIS & $1,498,258$ & $1,954,829$ & $2,169,715$ & $2,145,283$ \\
Exports, based on HWIS & 159,834 & 254,964 & 292,326 & 259,521 \\
Exports, from OSMA & 52,009 & 74,880 & 71,841 & 90,115 \\
\hline Total in-state generation & $1,550,267$ & $2,029,709$ & $2,241,556$ & $2,235,398$ \\
\hline Total exports & 211,843 & 329,844 & 36,4167 & 349,636 \\
\hline
\end{tabular}

the lower level (firms) assumes the initial taxes are substantially correct, and they plan their pollution control program which may take several years to complete, and it is largely irreversible once in place.

Kolstad[24] formulated his Four Corner case study in terms of a stochastic bilevel problem, but his interest was to derive some empirical properties for various air pollution regulations.

\section{Management of Hazardous Waste in California}

In the 1989 Capacity Assurance Plan, the state established a goal of managing California's waste within the state and limiting exports to 1987 levels. While emphasizing waste minimization and source reduction as the preferred way of managing hazardous waste, the plan saw a need for additional treatment capacity for incineration of liquids, sludges and solids, and projected that several new incineration facilities would be built. However, all proposals for incineration facilities listed in the 1989 and 1992 CAPs as pending have since been withdrawn. Waste exports have increased significantly ${ }^{1}$ (see Table 1), due in part to the lack of in state capacity for treating incinerable waste and a hazardous waste fee structure that encourages out-of-state disposal. The state's 1992 Capacity Assurance Plan emphasizes California's participation in the Western States Regional Agreement on Capacity Assurance, a tacit admission of California's continuing dependence on waste exports.

The state has continued to pursue waste minimization and source reduction as a way of balancing waste generation and treatment capacity. Funding is provided for local governments to develop waste minimization programs and to assist small businesses through loans for implementing waste minimization [35]. Hazardous waste generators are required to prepare waste management plans that identify hazardous waste streams and potential source reduction alternatives, formulate a plan for source reduction, and periodically review it [38]. In 1991, the Department of Toxic Substance Control initiated a review of these plans from four industry groups thought to offer the greatest potential for reducing incinerable wastes.

The DTSC promotes waste minimization and source reduction through a series of industry-specific waste minimization 'audit-studies', a waste recycler's catalog, 
the California Waste Exchange, and a variety of research and outreach efforts. Many studies, including the department's 'Incinerable Hazardous Waste Minimization Project', indicates that large reductions in hazardous waste generation can be achieved by implementing available pollution prevention and waste reduction measures.

\section{Development of a Decision Support Model}

This paper is concerned with developing a model to aid in regional hazardous waste management planning. The model cannot incorporate all the factors that need to be considered in regional waste management planning, such fairness or desirability of waste treatment versus waste reduction. Hence, the model is intended as a support tool to assess the impact of various policy alternatives rather than as a source of final answers.

In section 3.4, we highlighted the fundamental difficulties with assuming a complete cooperation between the firms and the Central Authority (CA). It is clear that the major difficulty the CA faces, is defining an objective that would increase the social benefit while satisfying the desire of the firms to maximize their profit. We attempt to take a step toward a more realistic model of an economy where the central authority has control over a subset of decision variables (e.g., prices) and the firms control the other variables (e.g., production).

It is reasonable to assume that the $\mathrm{CA}$ has no direct control over such decision variables as source reduction, or amount of on-site recycling. Rather, it can only set certain charges, issue permits, or designate a certain capacity for an off-site facility. This observation split the problem into two: firms and the CA with a hierarchical structure in which a decision maker (CA) at one level of a hierarchy may have an objective function; and the decision spaces are determined, in part, by other level (firms). This leads to a model for the operation of a firm as it relates to waste generation. Given a particular set of prices for offsite treatment (including transportation cost, fees and taxes), what is the firm's demand for offsite waste treatment?

\subsection{Risk Assessment}

One the most difficult aspect of this decision support model is the assessment of risk and more specifically quantification of risk. In general, emission is caused both by production activities and treatment methods. These emissions are converted by the environment into pollution concentration which vary continuously over space and time. Evaluating the damage these pollution concentrations have had on human and environment is of particular concern when forming a robust environmental policy. Risk assessment measures both risk acceptance, or appropriate level of safety and risk aversion, or methods of avoiding risk that can be used as alternatives to involuntary exposure. Identifying the risk associated with certain product may 
help in forming policies curbing the production or use of such materials. The risk assessment should not stop at measuring only the health and life, such as those resulting in morbidity and premature death, but it should also identify short and long term environmental and economical impact.

The process of risk evaluation for hazardous waste disposal and treatment greatly depends on the technology used and the exposure pathway. In particular, in absence of an alternate technology (e.g., replacing solvent by water-based cleaner) there are many possible point of hazards. We must evaluate the hazard level during and after treatment as well as the possible long run risk to the environment from the disposal of residuals. The treatments and potential hazards points are illustrated in Figure 1.

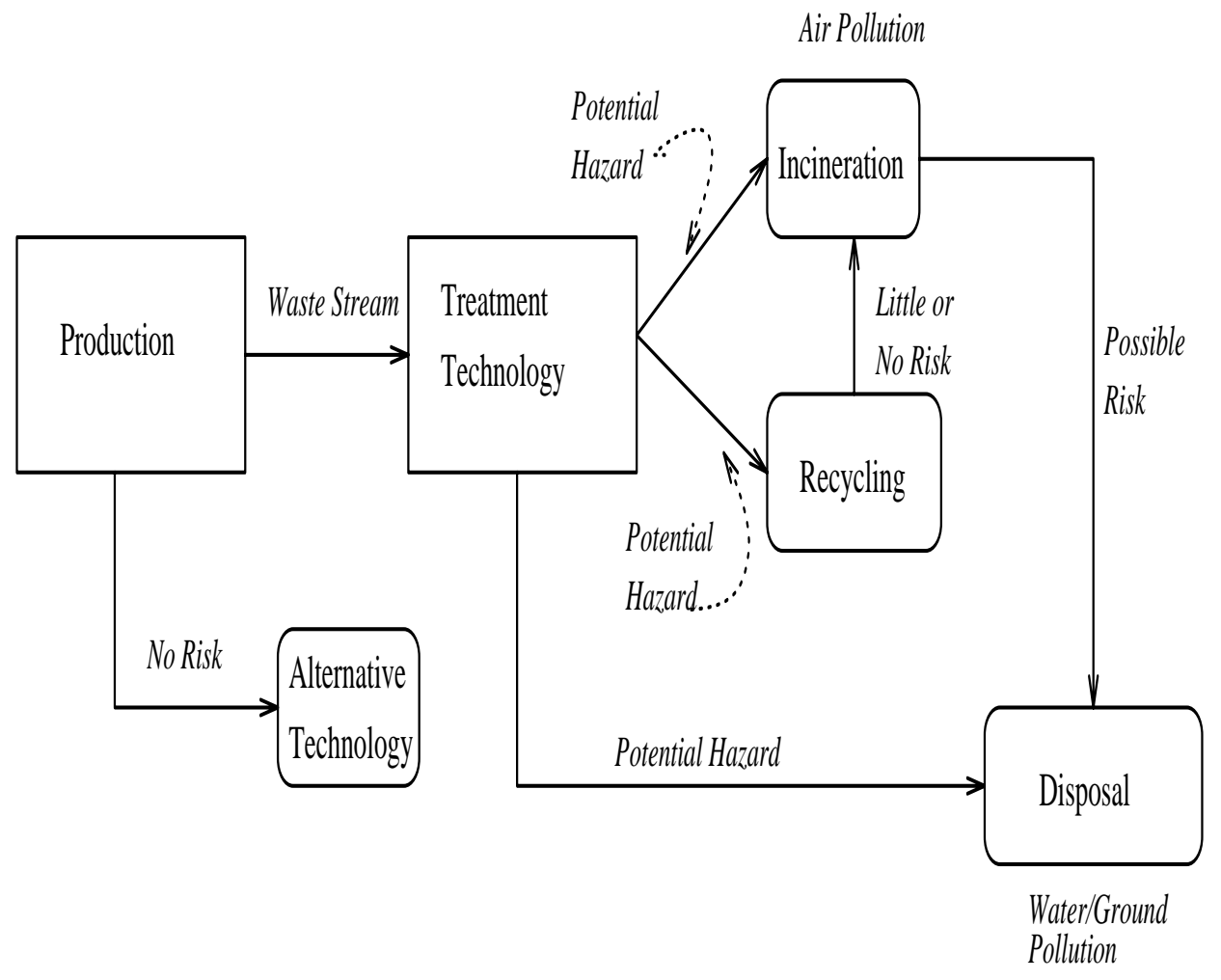

Figure 1. Risk Evaluation for Hazardous Waste Management

Toxicology and epidemiology can provide quantitative data on the relation between the dose(concentration) and response. Several formal and informal methods are available in estimating a quantitative relationship [28]. In developing a quantitative model we must focus on the quantification of risk in terms of human health. The precise question is how pollution affect illness and death rates, including partial 
disability, missed work and expenditures on health. One of the major problems in attempting to answer these questions is the lack of theoretical model specifying the way pollution affects health. For example, in terms of air pollution, the predominant effect is more subtle and relates to chronic diseases. Although the principal effect of air pollution is respiratory diseases, the human body is complex enough so that other chronic diseases, such as heart disease, are aggravated.

An additional difficulty is the methodology used in risk assessment. In particular, it has been argued (for example, see [27]) that investigating morbidity is more reasonable than examining mortality since death is the end of a complicated sequence that starts with an initial disease and may evolve in many ways. Unfortunately, data on morbidity rates, absence rates and health expenditure are not extensively available. There are, of course, other factors such as Urban living, life style, and errors in data collection that contribute to computing a damage function.

Adding to an already difficult problem is the fact that with a few notable exceptions, as in the case of asbestos, the determination of human health hazards must be assessed primarily on the basis of animal studies which are both costly and time consuming. Some specific sample costs and testing methodologies are presented in a report for the Office of Pesticides and Toxic Substances [12].

In our development of a decision support system, we will rely on developing a conceptual damage function that can be set by policy makers according to availability of data. Accordingly let $\psi(\cdot)$ denote pollution concentration from production, recycling and incineration. Because our only use of pollution concentration information is as an argument in pollution damage function, the specific nature of $\psi$ is governed by the damage function, $\delta(\psi)$. Therefore, if pollution damage is a function of annual average or annual maximum concentration in a region, the $\psi$ can be one dimensional. If, however, $\delta$ is a nonlinear function of concentration at all points in a region or regions over all points in time during a year, the $\psi$ will be a finite approximation to those concentrations.

\subsection{Hierarchical Decision Making}

The central authority, in order to encourage source reduction, may adopt a policy of rewarding firms for each unit of source reduction beyond some lower limit set by the CA. At the same time, the CA desires to punish firms who fail to meet the minimum source reduction standard and for shipping hazardous waste to offsite incinerators. The firms, of course, incur other cost other than the penalty (tax) set by the CA. The firms, in planning their waste management policy, need to consider such costs as the onsite recycling cost (including the setup and operating costs) and offsite recycling and incineration costs. Notationally, let $x_{i w}$ denote the quantity of waste type $w, w=1, \ldots, W$, firm $i, i=1, \ldots, I$, sends for onsite recycling, and similarly let $u_{i w r}$ and $v_{i w r}$ denote the quantity of offsite recycling and incineration of waste type $w$ produced by firm $i$ and shipped to region $r, r=1, \ldots, R$, respectively. Recycling processes leave certain quantity of residual which need to be incinerated. Therefore, let $\alpha_{i w}, i=1, \ldots, I, w=1, \ldots, W$, denote the fraction of residual from 
onsite recycling, and let $\beta_{w r}$ denote the fraction of residual from offsite recycling. The per unit costs of onsite recycling, offsite recycling and offsite incineration are denoted by $c_{i w}, R C_{r w}$ and $I C_{r w}$, respectively. The total cost to each firm is therefore denoted by

$$
T C_{i}=\sum_{r, w}\left[c_{i w} x_{i w}+R C_{r w} u_{i w r}+I C_{r w}\left(\alpha_{i w} x_{i w}+\beta_{w r} u_{i w r}+v_{i w r}\right)\right]
$$

Let $s_{i w}=\alpha_{i w} x_{i w}+\sum_{r}\left(\beta_{w r} u_{i w r}+v_{i w r}\right)$ denote the total waste $w$ earmarked for incineration by firm $i$ and let $L_{i w}$ denotes the lower bound set by the CA for the waste type $w$ for each firm $i$. The CA may attempt to encourage the reduction of $s_{i w}$ by setting up a tax/reward system. For example, it may tax each firm for any value of $s>0$, or may reward each firm for source reduction by paying an amount for each unit of $L_{i w}-s_{i w}$. Notationally, let $\rho_{w}$ denote the per unit price CA is paying each firm for reduction of waste type $w$, and let $\lambda_{w}$ denote the per unit tax the CA levies against firms who generate beyond the lower limit set by law. It may be that this tax/reward strategy could only be applied to a certain waste type. Let $\Omega$ be a set of wastes eligible for tax/reward scheme. Benefit to each firm is then

$$
B_{i w}\left(s_{i w}\right)= \begin{cases}\lambda_{w}\left(L_{i w}-s_{i w}\right) & \text { if } L_{i w}-s_{i w} \leq 0 \\ \rho_{w}\left(L_{i w}-s_{i w}\right) & \text { if } L_{i w}-s_{i w}>0\end{cases}
$$

Therefore the lower level objective function is expressed as follows

$$
\min \sum_{i}\left(T C_{i}-\sum_{w \in \Omega} B_{i w}\left(s_{i w}\right)\right)
$$

Firms are constrained by the capacity of each of the facilities available to them, any environmental laws on source reduction, and other physical constraints. In a decision support model, we can assume a fixed quantity of waste generated at the initial iteration and then revised this quantity to play different scenarios of waste reduction goals. If we denote the initial quantity of waste $w$ generated by each firm as $q_{i w}$ then each firm has the following constraint

$$
\sum_{r}\left[u_{i w r}+v_{i w r}\right]+x_{i w} \geq q_{i w}
$$

A flexible model should not mandate the existence of on- and offsite facilities, rather the solution to the optimization should indicate the need for such facilities. Let $\mathrm{cap}_{i}$ denote the possible capacity of an onsite recycling, and let $C a p_{r}$ and $C A P_{r}$ denote the offsite recycling and incineration capacities in region $r$ respectively. Then the three capacity constraints are as follows 


$$
\begin{aligned}
\sum_{w} x_{i w} & \leq \operatorname{cap}_{i} y_{i}, \text { for all } i \\
\sum_{i w} u_{i w r} & \leq C a p_{r} z_{r}, \text { for all } r \\
\sum_{i w}\left[\alpha_{i w} x_{i w}+\beta_{w r} u_{i w r}+v_{i w r}\right] & \leq C A P_{r} t_{r}, \text { for all } r
\end{aligned}
$$

where $y_{i}, z_{r}$ and $t_{r}$ are the binary decision variables.

The upper level (the central authority) has its own objective to optimize. It is conceivable that the central authority may wish to minimize the total waste treatment costs and pollution damage cost incurred to the region through the necessity of meeting some predetermined source reduction standard. These costs include both the local(on-site) treatment cost function $\mathrm{f}(\cdot)$, regional recycling and treatment cost functions $\mathcal{H}(\cdot)$ and $\mathcal{L}(\cdot)$, respectively and the premium cost $p$. Thus, the upper level objective function can be expressed as follows

$$
\begin{aligned}
\min _{\lambda, p} & \sum_{i, w} f_{i w}\left(x_{i w}\right)+\sum_{w r} \mathcal{H}_{w r}\left(\sum_{i} u_{i w r}\right) \\
& \sum_{w r} \mathcal{L}_{w r}\left(\sum_{i}\left[\alpha_{i w} x_{i w}+\beta_{w r} u_{i w r}+v_{i w r}\right]\right)+\delta(\psi)
\end{aligned}
$$

where $\delta(\psi)$ denote the pollution damage cost.

\subsection{Social Welfare Model}

Our second model is to maximize the social welfare of the region and is based partly on Kolstad's ([24]) air pollution control model. One way of dealing with social welfare is by the idea of economic surplus for the region. Let's define the economic surplus ES, in the absence of environmental regulation as the integral under all inverse demand functions from zero up to consumption level less producers' cost.

$$
E S(g, q)=\sum_{i=1}^{n}\left[\int_{0}^{g_{i}} \hat{P}_{i}(\rho) d \rho-C_{i}\left(g_{i}, q_{i}\right)\right]
$$

where $\hat{P}_{i}(\rho)$ is the inverse demand function and $C_{i}\left(g_{i}, q_{i}\right)$ is the i-th producer's cost with $g_{i}$ and $q_{i}=\left(q_{i 1}, \ldots, q_{i W}\right)$ denoting the output level and the vector of waste quantity respectively.

The role of the $\mathrm{CA}$ is to choose a regulation so that when firms respond to the regulation, social welfare is maximized. One such welfare is defined as economic surplus (1) less pollution damage. Therefore the CA's objective is to choose a regulation that maximizes welfare. 


$$
W=E S(g, q)-\delta(\psi) .
$$

In promulgating a regulation, $\mathrm{r}$, output levels, $g(r)$ and $q(r)$ will be determined by the market in response to the regulation $\mathrm{r}$. Let the profit function $\mathrm{PF}$ for each firm be defined as revenue minus cost where cost may include regulatory charges.

$\max \quad P F$

$$
\begin{array}{ll} 
& q_{i w}, u_{i w r}, v_{i w r} \text { satisfy } r \\
& \sum_{r}\left[u_{i w r}+v_{i w r}\right]+x_{i w} \geq q_{i w} \\
\text { (L2) } \quad & \sum_{w} x_{i w} \leq c a p_{i} y_{i}, \quad \text { for all } i \\
& \sum_{i w} u_{i w r} \leq C a p_{r} z_{r}, \text { for all } r \\
& \sum_{i w}\left[\alpha_{i w} x_{i w}+\beta_{w r} u_{i w r}+v_{i w r}\right] \leq C A P_{r} t_{r}, \text { for all } r
\end{array}
$$

and the $\mathrm{CA}$ optimization model is to seek a regulation $r$, within a set of feasible regulations $\mathrm{R}$, which maximizes welfare, given the manner in which the economy response to such regulations (L2). Then the CA's problem is to

$$
\max _{r \in R} W(r)
$$

where the value of $\mathrm{W}$ is defined by $r$ indirectly through the optimization problem of the firms (i.e., (L2)).

Consider two types of emission regulations: emission fees and marketable emission permits. We assume both regulations are set before the firms have made their production decisions.

1. Emission Fee:

We may either impose an emission fee on all the hazardous wastes generated or just on those wastes that are send for incineration. (L2) is modified to account for the imposition of a fee on all hazardous waste at the source or a fee $\lambda$ for lack of source reduction.

$$
\begin{aligned}
& \text { Maximize }\left[P F-t \cdot \sum_{i, w} q_{i w}\right] \\
& \text { or, } \\
& \text { Maximize }\left[P F+\sum_{i, w \in \Omega} B_{i w}\left(s_{i w}\right)\right]
\end{aligned}
$$


Equation (3) refers to charging all hazardous wastes generated, and equation (4) refers to previously defined partial charges and incentive.

2. Marketable emission permits:

We may simulate the action of a marketable permit system through a constraint on (L2). Let $M_{w}$ be the issuance of emission permits then we may append the following to the constraint set of (L2)

$$
\sum_{i=1}^{n} q_{i w} \leq M_{w} \quad w \in W
$$

Permit trading may be assumed to occur over the entire economy as in equation (5) or trading may occur only within zones (regions).

\subsection{A Brief Note on Centralized Planning}

The task of developing a full decision support model requires that we consider the instances where cooperations between the central authority and the firms may be possible. Consequently, we present brief descriptions of microeconomic model as well as a system optimization model that may be useful at certain instances of policy making.

Our fist model considers the problem from the point-of-view of the firms where as before in a given geographical region many firms operate and produce certain amount of goods which are not necessarily identical. As a by product these firms' activities a certain quantity of hazardous waste is generated which need to be managed.

Let $g$, denote the output level of a firm which uses factors of production $z_{1}, \ldots, z_{J}$. Let $p_{j}, j=1, \ldots, J$, denote the per unit price of factor $j$ and let $\phi(z)$ denote the firm's production function, where $z=\left(z_{1}, \ldots, z_{J}\right)$. Let $P(g)$ denote the firm's inverse demand function for its product (i.e., $P(g)$ is the per unit price consumers will pay for a total of $g$ units). Let $q(z)=\left(q_{1}(z), \ldots, q_{w}(z)\right)$ where $w \in W$ denote the vector of resulting hazardous wastes. In this model firms may manage their waste using on-site and off-site facilities, as well as having waste minimization as an additional option. The usual concept of 'waste minimization', at its initial state, is that the firm may have a few alternatives with respect to the nature of the very technology that the firm may use to produce its output. We proceed, formally, to model this important aspect as follows. Let there be $T$ technologies, indexed by $t=1, \ldots, T$, available to the firm and let $\phi_{t}, t=1, \ldots, T$, denote the corresponding production functions. Let $t=1$ denote the technology the firm is currently using to produce its output. Assume also that only one technology may be used by the firm. Denote

$$
y_{t}= \begin{cases}1 & \text { If technology } t \text { is used, and } \\ 0 & \text { Otherwise }\end{cases}
$$


and let $T_{1 t}$ denote the cost of switching from the current technology to another technology denoted by $t, t=2, \ldots, T$. Let $q_{t}(z), t=1, \ldots, T$ denote the firm's waste vector when using technology $t$.

In this conceptual framework, the objective of all firms is to maximize the revenue minus the productions cost, change of technology cost, pollution damage cost and the operating cost (TC).

$$
\max \sum_{i \in I} P_{i}\left(g_{i}\right) \cdot g_{i}-\sum_{i \in I} \sum_{j \in J} p_{i j} \cdot z_{i j}-\sum_{i \in I} \sum_{t \in T} T_{1 i t} \cdot y_{i t}-\delta(\psi)-\sum_{i \in I} T C_{i}
$$

The constraint set is same as the model of section 5.2 with an addition of the production constraint

$$
\sum_{t=1}^{T} \phi_{i t}\left(z^{i}\right) \cdot y_{i t}-g^{i} \geq 0 .
$$

The second model is a simple system optimization model where the problem is approached from the point-of-view of the central authority. In this area of waste management where there is a total cooperation between firms and the central authority, the $\mathrm{CA}$ is in the control of all the location and allocation decisions. This approach will try to minimize the total cost to the system (i.e., minimize $\sum_{i \in I} T C_{i}$ ) given the capacity constraints for all the on- and off-site facilities. In this model, the optimal solution, if exists, will dictate the behavior of each firm, even though such optimal solution may not be optimal for a particular firm. Therefore, two very important questions come to mind, who owns these facilities? And how does the CA distribute the costs efficiently?

We don't allow the sale of excess capacity between the firms, so each on-site facility is owned and paid for by the corresponding firm. It is in the off-site facilities where the ownership question arises. One scenario is cooperative ownership by all the users (firms), another is the ownership by the CA. The third option is a private ownership. In the first two scenarios, the cost functions are the set-up cost plus the operating cost distributed 'efficiently' between the firms. In the latter scenario a closer attention, is needed.

If the off-site facilities are owned privately but are fully controlled by the CA, it would be the same as the CA operating these facilities. Therefore, we must assume that after the CA has decided on the size, number and the location of the facilities, it will allow 'outside' operation and ownership of these potential facilities through some sort of allocation system such as marketable permit system. These permits may incorporate two types of operating systems, private (i.e., allow some type of profit maximization) or public (i.e., zero profit scheme).

Now, whether we employ the marginal revenue equal marginal cost rule (profit maximization), price equal average cost rule under economies-of-scale or price equal marginal cost rule under diseconomies-of-scale (public utility), we are faced with the difficulties of computing accurate demands for these off-site facilities, since the 
off-site cost functions are no longer the set-up cost plus operating cost. The new off-site cost functions are just the per unit prices charged by these facilities. It is immediate that firms' demand for the off-site facilities depends on the off-site prices which in turn depends on the demands by the firms. It is unrealistic and inadvisable for the CA to set arbitrary prices (hence the reason for the bilevel programming model) and then adjust these prices as the off-site facilities respond. The building and planning of such facilities, alone, take years and the firms' production decisions may not be so easily changed.

To remedy this cyclical problem, we must assume a full capacity use of each potential facility. We must further assume that each facility is chosen from a discrete set of facility sizes (an assumption that is more true to reality). We may then compute the per unit prices which maximizes the potential owner's profit for each facility size.

In the case of public utility, we set the price equal the average cost under economiesof-scale or price equal the marginal cost under diseconomies-of-scale with a full capacity operation. In the case of a profit maximizing industry, the CA must have some knowledge of these industries revenue functions. Currently, operating facilities may give some indication of desired profit margins, or the permit issuing $\mathrm{CA}$ may set a ceiling on the profit margin (e.g., $10 \%$ above cost).

If all the cost functions are convex, the problem becomes 'trivial' in the sense of Generalized Bender's Decomposition [13] where the decision variables of the constraint set are partitioned into a discrete variable space and the continuous variable space.

The difficulty, beyond the large size of the problem, is where there is an economiesof-scale in play. It is reasonable to assume that in some of these facilities the marginal cost may decrease as more quantity of waste is sent to them which yield a nonconvex optimization problem. The difficulty with this type of problem is that current solution techniques may not be able to find the global (optimal) solution to the problem. The nonconvexity combined with integer variables, which create a discontinuous feasible region, will make the problem even more difficult to solve. Yet, it is exactly this economies-of-scale in the off-site facilities that makes the model more realistic, and in certain cases it is to each firm's benefit to pool their undesirable products together in order to get a 'cheaper' per unit cost.

As we have mentioned earlier this model is appropriate when the decisions are centralized. In this model the off-site facilities play the role of the suppliers and the firms have some fixed demand. The prices for the off-site facilities depend on the different types of ownership scenarios and the benefit function derived from these scenarios. A benefit measure would be the revenue in a private industry, but in a public facility the is measured by adding to the revenue the additional benefit accruing to consumers from receiving a price lower than the maximum they would be willing to pay. In another word the gross benefit to the society is just the 'willingness-to-pay'.

Let 
- $\quad P(u, v)$ be the joint inverse demand function for recycling and incineration respectively.

We can mathematically state the benefit to a private and public industries as follows:

1. Private:

For a private enterprise the gross benefits are from the revenues, thus the private benefit is

$$
B(u, v)=R(u, v)=P(u, v) \cdot(u+v) .
$$

2. Social benefit:

For a social enterprise, we define total benefit as the consumers' 'willingness to pay' plus the producers revenue. Suppose for the incremental unit added to a demand of $\nu_{1}<u$ and $\nu_{2}<v$, the 'willingness-to-pay' is the price $P\left(\nu_{1}, \nu_{2}\right)$ and therefore the consumers' surplus is

$$
\begin{aligned}
S(u, v) & =\int_{0}^{u} \int_{0}^{v}\left[P\left(\nu_{1}, \nu_{2}\right)-P(u, v)\right] d \nu_{1} d \nu_{2} \\
& =\int_{0}^{u} \int_{0}^{v} P\left(\nu_{1}, \nu_{2}\right) d \nu_{1} d \nu_{2}-R(u, v)
\end{aligned}
$$

and the total social benefit is just consumers' surplus plus revenue,

$$
B(u, v)=S(u, v)+R(u, v)=\int_{0}^{u} \int_{0}^{v} P\left(\nu_{1}, \nu_{2}\right) d \nu_{1} d \nu_{2} .
$$

Now we can introduce a model that considers the benefit to all firms and at the same time regards the pollution damage and the benefits to the region. It is easy to see that the goal of the CA is to maximize the net benefit, but the difficulty is whose benefit should the CA consider?

It is clear that under any pricing scenario the monetary benefit to the off-site facility is a cost to the firms, and thus the off-site benefits and the firms' benefits are not additive. Therefore, our attempt should be to try to maximize the firms' revenue (benefit) minus the on-site, off-site and the pollution damage cost. Of course, the off-site costs are just the per unit prices set by the off-site facilities under different ownership scenarios of equations (6) and (7). 
Table 2. Hazardous Waste Generation and Capacity for ABAG Counties(Tons)

\begin{tabular}{|l|r|r|r|r|r|}
\hline \multirow{2}{*}{ County } & \multicolumn{4}{|c|}{ Hazardous Waste Generation } & Treatment \\
\cline { 2 - 5 } & \multicolumn{1}{|c|}{1988} & \multicolumn{1}{|c|}{1989} & \multicolumn{1}{|c|}{1990} & \multicolumn{1}{c|}{ Capacity } \\
\hline Alameda & 97,502 & 89,599 & 86,400 & 88,282 & 80,520 \\
Contra Costa & 65,306 & 95,172 & 135,287 & 63,733 & 0 \\
Marin & 1,993 & 3.253 & 2,983 & 3,463 & 2,430 \\
Napa & 1,200 & 1,801 & 1,323 & 1,663 & 0 \\
San Francisco & 44,167 & 64,679 & 50,787 & 39,551 & 76,000 \\
San Mateo & 69,645 & 90,919 & 113,828 & 114,983 & 78,900 \\
Santa Clara & 92,449 & 83,804 & 95,308 & 111,041 & 68,773 \\
Solano & 14,668 & 25,108 & 38,587 & 32,049 & 0 \\
Sonoma & 7,603 & 8,743 & 36,108 & 8,648 & 0 \\
\hline Total & 394,533 & 462,808 & 560,611 & 463,413 & 306,643 \\
\hline
\end{tabular}

Source: Waste generation computed from summary tapes of Hazardous Waste Manifest Data from Department of Toxic Substances Control [26].

\section{Application to the San Francisco Bay Area}

Our models have been implemented, for a limited set of waste streams (see Appendix A.1), using San Francisco Bay area as a case study. The nine counties of this region, which form the Association of Bay Area Governments (ABAG), account for over $25 \%$ of the waste generated in California. Table 2 shows the total offsite disposal of hazardous wastes and current treatment capacity in each county.

The current implementation focuses on incinerable wastes, due to the acute shortage of treatment capacity for them and the limited number of treatment and disposal options. The model includes:

- 20 different waste types, based on California waste codes.

- Options for waste management are on- and off-site recycling and incineration, plus two disposal options for the residuals.

- Offsite facilities in three discrete sizes.

- Capital and operating costs are given for each type and size of facility, based on an EPA studies [10], [11]

- Transportation costs are based on mileage, using the distance between the centers of the counties as average distances, and a cost of $\$ 0.23 /$ ton-mile.

- Waste generation data for each waste type in each ABAG county, computed from the 'Tanner tapes' of DTSC's Hazardous Waste Information System.

- Waste generation in each county is divided among small, medium and large firms, with the assumption that they account for 20,30 and 50\%, respectively, of the total generation of each waste type. 
Conceptually, the decision support model will consider the regional hazardous waste problem and depending on the desire of the policy makers and/or the availability of the information partition the problem into centralized or decentralized planning (see Figure 2). Many solution techniques and commercial softwares are available for the linear or the convex optimization formulations of the centralized planning. Appendix A.2 illustrates an example of a system model using GAMS [6] modeling language. One of the basic results of this model has been the dominance of the transportation costs. Further studies is war ranted and is underway. In case of nonconvex optimization problems (i.e., presence of economies-of-scale in the objective), there are less choices and specialized programs must be developed. For more detailed description of these technique see a monograph by Horst and Tuy [20].

If it is desired to develop optimal taxing or pricing scheme, we must formulate the problem as a hierarchical model. In the case of the linear upper (i.e., CA) objective and the linear lower (i.e., firms) objective, there are half a dozen algorithms with varying degrees of success (e.g., see Bard and Moore [3], Hansen et. al. [18], Amouzegar and Moshirvaziri [2]). To the best of our knowledge, they can handle about 100 leader variables and 100 follower variables and 50 constraints. When discrete variables are added, the manageable problem size shrinks by nearly an order of magnitude. In case of nonlinear objectives, only a few algorithms exist (e.g., see Vicente and Calamai [44]) but they can only handle small size problems. Naturally, any final analysis depends on the political and physical considerations.

\section{Summary and Remarks}

We have developed a decision support model in order to aid policy makers in developing a sound managerial decision regarding an important issue facing many industrialized nations. This paper gives a brief history of methods developed in the area of environmental economics including recent attempts in using optimization techniques. In this paper, we have recognized the interaction between the central player and the others by developing a hierarchical model that deals with setting optimal taxing schemes. Issues such as social welfare, risk assessment and cooperation with firms are also addressed.

A single level model (i.e., where the CA controls all decision variables) is implemented in GAMS, a modeling and optimization package which enables a concise algebraic description of complex mathematical programming models. The current implementation contains more than 150,000 continuous variables and 300 binary variables. Due to the size of the problem, a smaller Hierarchical model is implemented using the algorithm developed by Amouzegar and Moshirvaziri [2]. This algorithm has been coded on Matlab using the subroutines developed in [33]. Unlike linear or even integer programming problems where we are able to solve very large scale problems, bilevel models need to be scaled down due to their inherent complexities. Hence the development of a decision support system where we are more concerned with a model that can interact with a decision maker. 


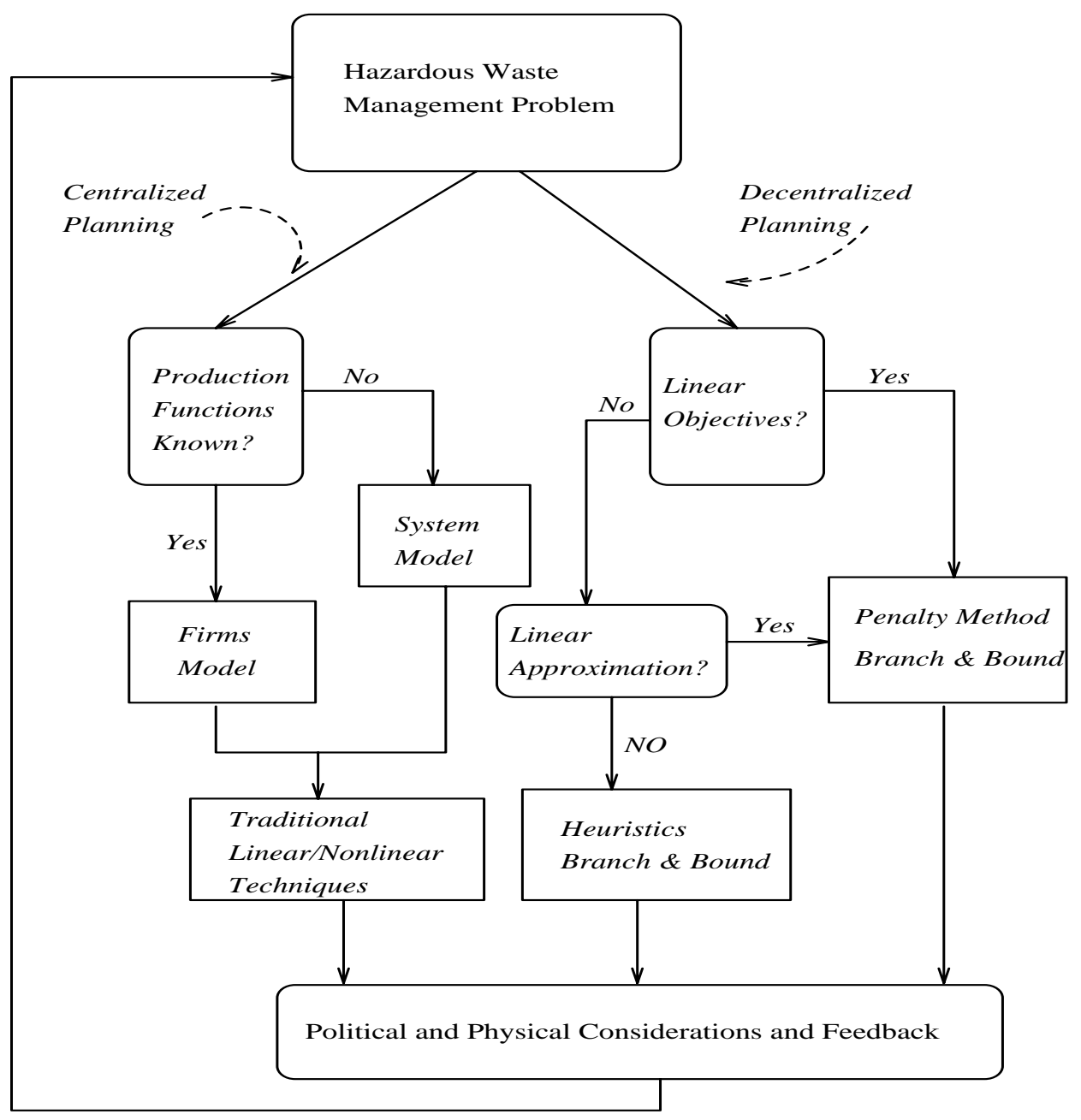

Figure 2. Decision Support Flow Chart

\section{Notes}

1. Sources: 'Tanner Tapes' of the California Hazardous Waste Information System (HWIS) plus data from the Out-of-State Manifest System (OSMA), obtained from the Department of Toxic Substances Control.

\section{References}

1. M.A. Amouzegar and S.E. Jacobsen. Analysis of mathematical modeling methods for regional hazardous waste management. Technical Report ENG-95-147, Optimization and Communi- 
cations Systems Laboratory, Department of Electrical Engineering, University of California, Los Angeles, 1994.

2. M.A. Amouzegar and K. Moshirvaziri. A penalty method for linear bilevel programming problems. In A. Migdalas, M. Pardalos, and P. Värbrand, editors, Multilevel Optimization: Algorithms, Complexity and Applications, chapter 11. Kluwer Academic Publishers, 1997.

3. J. Bard and J. Moore. A branch and bound algorithm for the bilevel programming problem. SIAM Journal on Scientific and Statistical Computing, 11:281-292, 1990.

4. William Baumol and Wallace Oates. The Theory of Environmental Policy. Cambridge, M.A., Cambridge University Press, 2nd edition, 1988.

5. B. Beavis and I. Dobbs. Firm behaviour under regulatory control of stochastic environmental wastes by probabilistic constraints. Journal of Environmental Economics and Management, 14:112-127, 1987.

6. A. Brooke, D. Kendrick, and A. Meerhaus. GAMS: A User's Guide. Boyd \& Frazer.

7. Thomas D. Crocker. The structuring of atmospheric pollution control system. In Harold Wolozing, editor, The Economic of Air Pollution. W. Norton, New York, 1966.

8. J. H. Dale. Pollution, Property, and Prices: An Essay in Policy-Making. Toronto: University of Toronto Press, 1968.

9. G.B. Dantzig and P. Wolfe. Decomposition principle for linear programs. Operations Research, 8:101-111, 1960

10. DPRA Incorporated, St. Paul, MN. Baseline and Alternative Waste Management Cost Estimation for First Third Land Disposal Restriction, 1989. prepared for US EPA.

11. DPRA Incorporated, St. Paul, MN. Baseline and Alternative Waste Management Cost Estimation for Third Third Land Disposal Restriction, 1989. prepared for US EPA.

12. R. Evans, J. Bakst, and M. Dreyfus. Analysis of TSCA reauthorization proposals. Technical report, Office of Pesticides and Toxic Substances, U.S. EPA, Washington D.C, 1985.

13. A.M. Geoffrion. Generalized Bender's decomposition. Journal of Optimization Theory and Applications, 10:237-260, 1972.

14. G.W. Graves, G.B. Hatfield, and A. Whinston. Water pollution control using by-pass piping. Water Resource Research, 5(1):13-47, 1969.

15. G.W. Graves, D.E. Pingry, and A. Whinston. Application of a large scale nonlinear programming problem to pollution control. In AFIPS, 1971.

16. J. Y. Haimes, M. A. Kaplan, and M. A. Husar Jr. A multilevel approach to determining optimal taxation for the abatement of water pollution. Water Resource Research, 8(4):851860, 1972.

17. J. Hall and S.E. Jacobsen. Development of an economic analytical frame work for solid waste policy analysis. Technical report, Office of Research and Monitoring, U.S. EPA, Washington D.C., 1975.

18. P. Hansen, B. Jaumard, and G. Savard. New branch and bound rules for linear bilevel programming. SIAM Journal on Scientific and Statistical Computing, 13(5):1194-1217, 1992.

19. J. E. Hass. Optimal taxing for the abatement of water pollution. Water Resource Research, 6(2):353-365, 1970.

20. R. Horst and H. Tuy. Global Optimization. Springer-Verlag, 1993.

21. S.E. Jacobsen. Mathematical Programming and the Computation of Optimal Taxes for Environmental Pollution Control, volume 41 of Lecture Notes in Computer Science, pages 337-352. Springer-Verlag, 1975.

22. Allen Kneese. Water Pollution: Economic Aspect and Research Needs. Resources for the Future, Washington D.C., 1962.

23. Allen Kneese and Charles Schultz. Pollution, Price, and Public Policy. The Brooking Institution, Washington D.C., 1975.

24. C. D. Kolstad. Empirical properties of economic incentives and command-and-control regulation for air pollution control. Land Economics, 62(3):250-268, 1986.

25. Alan J. Krupnick. On marketable air-pollution permits: The case for a system of pollution offsets. Journal of Environmental Economics and Management, 10:233-247, 1983. 
26. R.S. Larson. Staff report. Technical report, San Francisco Bay Area Hazardous Waste Management Facility Allocation Committee, 1991.

27. L.B. Lave. Air pollution damage. In A. Kneese and B. Bower, editors, Environmental Quality Analysis, pages 213-244. The John Hopkins Press, 1973.

28. L.B. Lave. Methods of risk assessment. In L.B. Lave, editor, Quantitative Risk Assessment in Regulation, pages 23-54. The Brooking Institution, 1982.

29. Abba P. Lerner. The 1971 report of the president's council of economic advisers: Priorities and efficiency. American Economics Review, 61:527-530, 1971.

30. J. C. Liebman and W. R. Lynn. The optimal allocation of stream dissolved oxygen. Water Resource Research, 2(3):581-591, 1966.

31. M. K. Macauly, M. D. Bowes, and K. L. Palmer. Using Economic Incentives to Regulate Toxic Substances. Resources for the Future, Washington D.C., 1992.

32. W. David Montgomery. Markets in licenses and efficient pollution control programs. Journal of Economics Theory, 5:395-418, 1972

33. K. Moshirvaziri and M.A. Amouzegar. A Matlab linear programming tool for use in global optimization algorithms. Technical Report ENG-95-146, Optimization and Communications Systems Laboratory, Department of Electrical Engineering, University of California, Los Angeles, 1995.

34. Susan Rose-Ackerman. Effluent charges: A critique. Canadian Journal of Economics, 6(4):512-528, 1973.

35. State of California. Assembly Bill AB4294, and Senate Bill SB788. The Hazardous Waste Technology, Research, Development, and Demonstration Program (AB4294) and the Hazardous Waste Reduction Loan Program (SB788).

36. State of California. Health and Safety Code $\S 25155.5$.

37. State of California. Assembly Bill AB2948, 1986. This bill formed Articles 3.5 and 8.7 of the Health and Safety Code.

38. State of California. Senate Bill SB14, 1989. The Hazardous Waste Source Reduction and Management Review Act (SB14).

39. T.H. Tietenberg. Derived decision rules for pollution control in a general equilibrium space economy. Journal of Environmental Economics and Management, 1:3-16, 1974.

40. United States Environmental Protection Agency, Center for Environmental Research Information, Office of Research and Development. Permit Writer's Guide to Test Burn Data, Hazardous Waste Incineration, epa/625/6-86/012 edition, 1986.

41. United States Environmental Protection Agency, Office of Solid Waste and Emergency Response. The Waste System, 6/9-248/00766 edition, 1989. U.S. Government Printing Office.

42. United States Environmental Protection Agency, Pesticides and Toxic Substances (TS-779). The Toxic-Release Inventory, Executive Summary, epa/560/4-89-006 edition, June 1989.

43. United States Environmental Protection Agency, Washington D.C. Hazardous Waste Treatment, Storage, and Disposal Facility Report, 1985.

44. L. N. Vicente and P. H. Calamai. Bilevel and multilevel programming: A bibliography review. Journal of Global Optimization, 5(3), 1994.

45. Martin L. Weitzman. Prices vs. quantities. Review of Economic Studies, 41(4):477-491, 1974 . 


\section{Appendix}

\section{A.1. Waste Streams}

This appendix presents the 20 types of waste streams used in this paper. The numbers are the California Waste Category identification numbers.

\begin{tabular}{|c|c|c|}
\hline Waste Group & & California Waste Category \\
\hline \multicolumn{3}{|l|}{ Recyclable: } \\
\hline \multirow[t]{2}{*}{ Halogenated Solvents } & 211 & Halogenated Solvents \\
\hline & 741 & Liquids with Halogen \\
\hline Non-Halogenated & 212 & Oxygenated Solvents \\
\hline \multirow[t]{2}{*}{ Solvents } & 213 & Hydrogen Solvents \\
\hline & 214 & Unspecified Solvent Mixtures \\
\hline Oily Sludges & 222 & Oil/Water Separation Sludge \\
\hline \multirow[t]{2}{*}{ Waste oil } & 221 & Waste Oil and Mixed Oil \\
\hline & 223 & Unspecified Oil Containing Waste \\
\hline \multicolumn{3}{|l|}{ Non-recyclable } \\
\hline \multirow[t]{5}{*}{ Organic Liquid } & 133 & Aqueous with Total Organics $>10 \%$ \\
\hline & 134 & Aqueous with Total Organics $<10 \%$ \\
\hline & 341 & $\begin{array}{l}\text { Organic (Non-solvents) Liquids } \\
\text { with Halogens }\end{array}$ \\
\hline & 342 & Organic Liquids with Metal \\
\hline & 343 & Unspecified Organic Liquids Mixture \\
\hline \multirow{3}{*}{$\begin{array}{l}\text { Halogenated Organic } \\
\text { Sludges and Solids }\end{array}$} & 251 & Still Bottoms with Halogenated Organics \\
\hline & 351 & organic Solids with Halogens \\
\hline & 451 & Degreasing Sludge \\
\hline Non-Halogenated Organic & 241 & Tank Bottom Waste \\
\hline Sludges and Solids & 252 & Other Still Bottom Waste \\
\hline $\begin{array}{l}\text { Dye and Paint Sludges } \\
\text { and Resins }\end{array}$ & 271 & Organic Monomer Waste \\
\hline Miscellaneous Wastes & 331 & Off-Spec, Aged or Surplus Organics \\
\hline
\end{tabular}

\section{A.2. Data Structure}

This appendix describes the data used in the system formulation of the problem. 


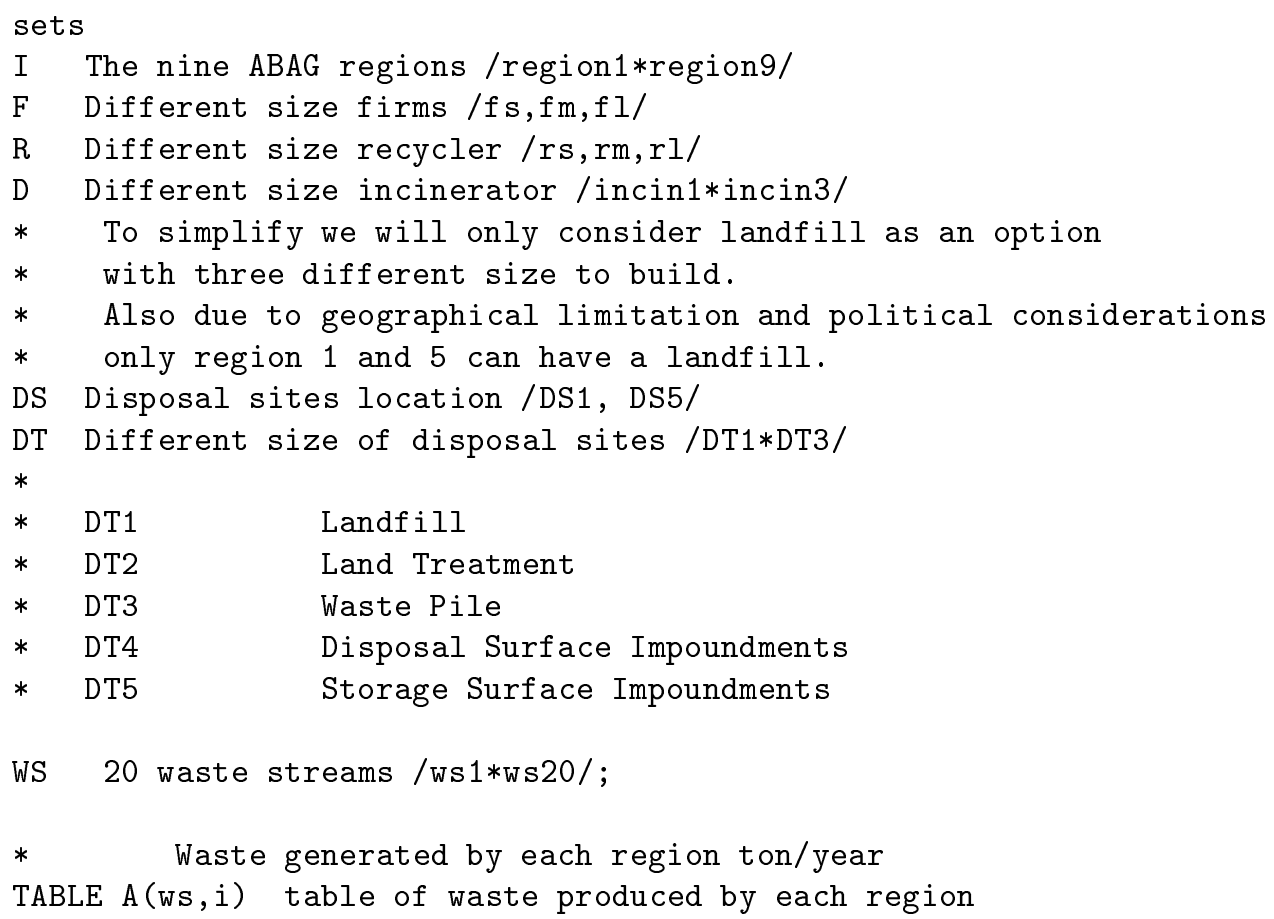

$\begin{array}{lrrrlrrrrr} & 1 & 2 & 3 & 4 & 5 & 6 & 7 & 8 & 9 \\ \text { ws1 } & 726.5 & 95.5 & 7.5 & 0.7 & 17.0 & 171.6 & 1950.0 & 45.7 & 258.9 \\ \text { ws2 } & 33.4 & 8.0 & 0.0 & 0.0 & 1.3 & 1.0 & 13.7 & 76.2 & 0.0 \\ \text { ws3 } & 809.5 & 89.6 & 8.0 & 8.2 & 33.3 & 214.6 & 3326.6 & 21.2 & 37.2 \\ \text { ws4 } & 2184.0 & 96.2 & 14.0 & 0.5 & 87.8 & 32.5 & 1642.0 & 8.2 & 1659.1 \\ \text { ws5 } & 2627.9 & 725.0 & 44.7 & 13.9 & 467.3 & 10123.6 & 6423.0 & 175.7 & 68.6 \\ \text { ws6 } & 19494.7 & 5889.7 & 85.9 & 49.6 & 1045.8 & 47243.1 & 12672.0 & 1982.9 & 675.7 \\ \text { ws7 } & 2602.4 & 4615.3 & 14.6 & 3.4 & 922.5 & 119.4 & 1259.7 & 1159.7 & 141.6 \\ \text { ws8 } & 125.2 & 59.2 & 0.0 & 1.5 & 21.2 & 58.9 & 204.1 & 0.0 & 4.8 \\ \text { ws9 } & 538.4 & 675.6 & 7.1 & 65.9 & 1376.7 & 602.9 & 577.5 & 38.9 & 52.7 \\ \text { ws10 } & 1.1 & 1.9 & 0.0 & 0.0 & 0.0 & .2 & 50.1 & 0.0 & 0.0 \\ \text { ws11 } & 7.9 & .6 & 0.0 & 0.0 & 1.2 & 0.0 & 29.8 & 0.0 & 0.9 \\ \text { ws12 } & 250.6 & 847.8 & 1.2 & 0.2 & 58.4 & 244.4 & 487.4 & 27.2 & 52.9 \\ \text { ws13 } & 429.5 & 2778.9 & 32.5 & 0.0 & 236.5 & 70.1 & 329.3 & 1129.8 & 8.8 \\ \text { ws14 } & 54.9 & 640.2 & 49.8 & 0.0 & 0.0 & 0.5 & 4.4 & 0.0 & 0.0 \\ \text { ws15 } & 7.7 & 12.3 & 0.0 & 0.0 & 0.8 & 0.0 & 33.9 & 0.0 & 0.0 \\ \text { ws16 } & 4.5 & 7.0 & 0.0 & 0.0 & 0.2 & 1.1 & 7.2 & 0.0 & 0.0 \\ \text { ws17 } & 1617.9 & 934.4 & 33.7 & 2.4 & 887.1 & 1686.5 & 568.9 & 161.2 & 125.6 \\ \text { ws18 } & 15.3 & 0.0 & 0.0 & 0.0 & 1.3 & 1.5 & 2.6 & 0.0 & 0.0 \\ \text { ws19 } & 48.0 & 7.4 & 0.0 & 0.0 & 1.3 & 0.1 & 56.3 & 2.7 & 0.0 \\ \text { ws20 } & 118.2 & 70.5 & 1.0 & 0.0 & 26.0 & 15.5 & 59.9 & 35.8 & 0.4 \text {; }\end{array}$




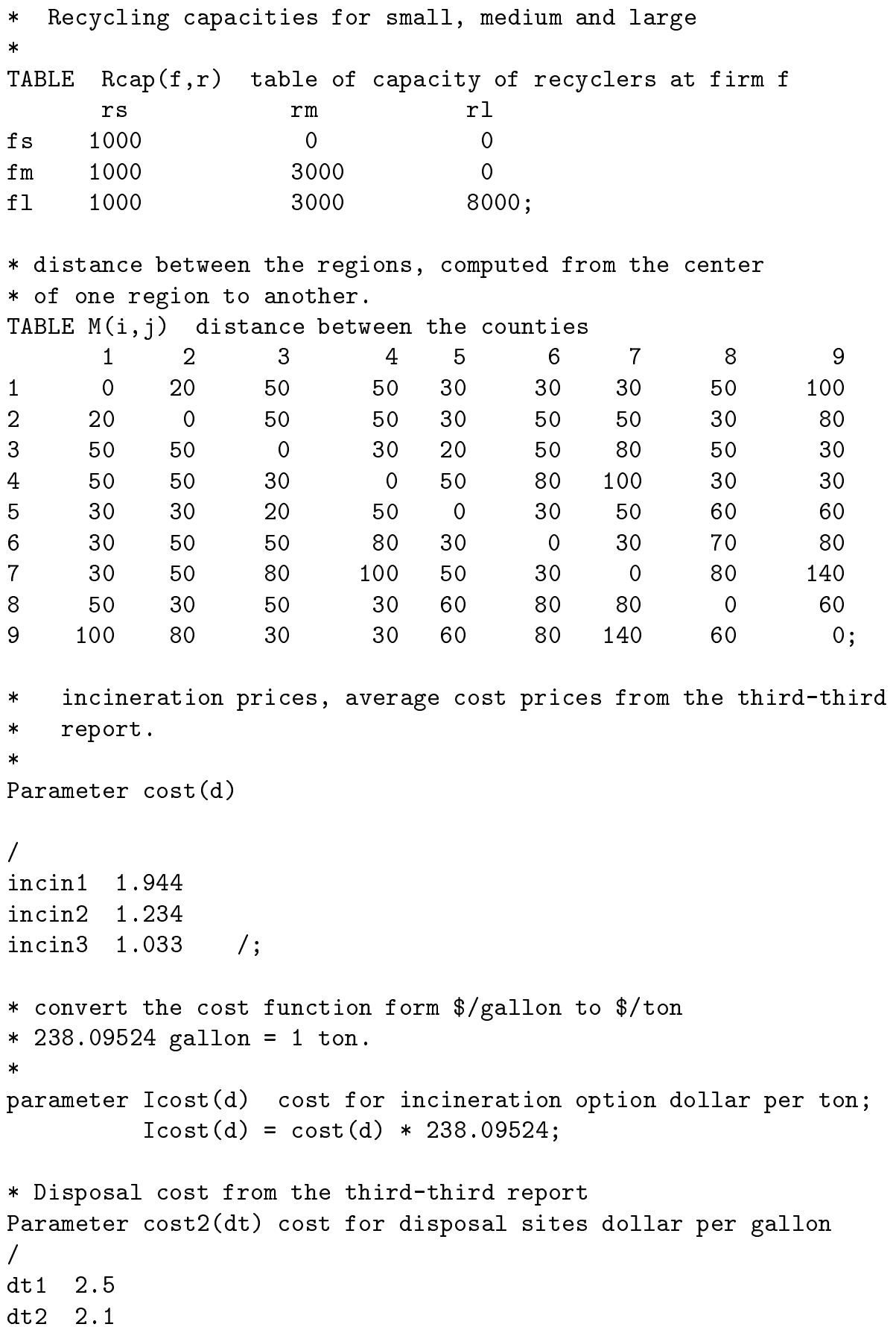




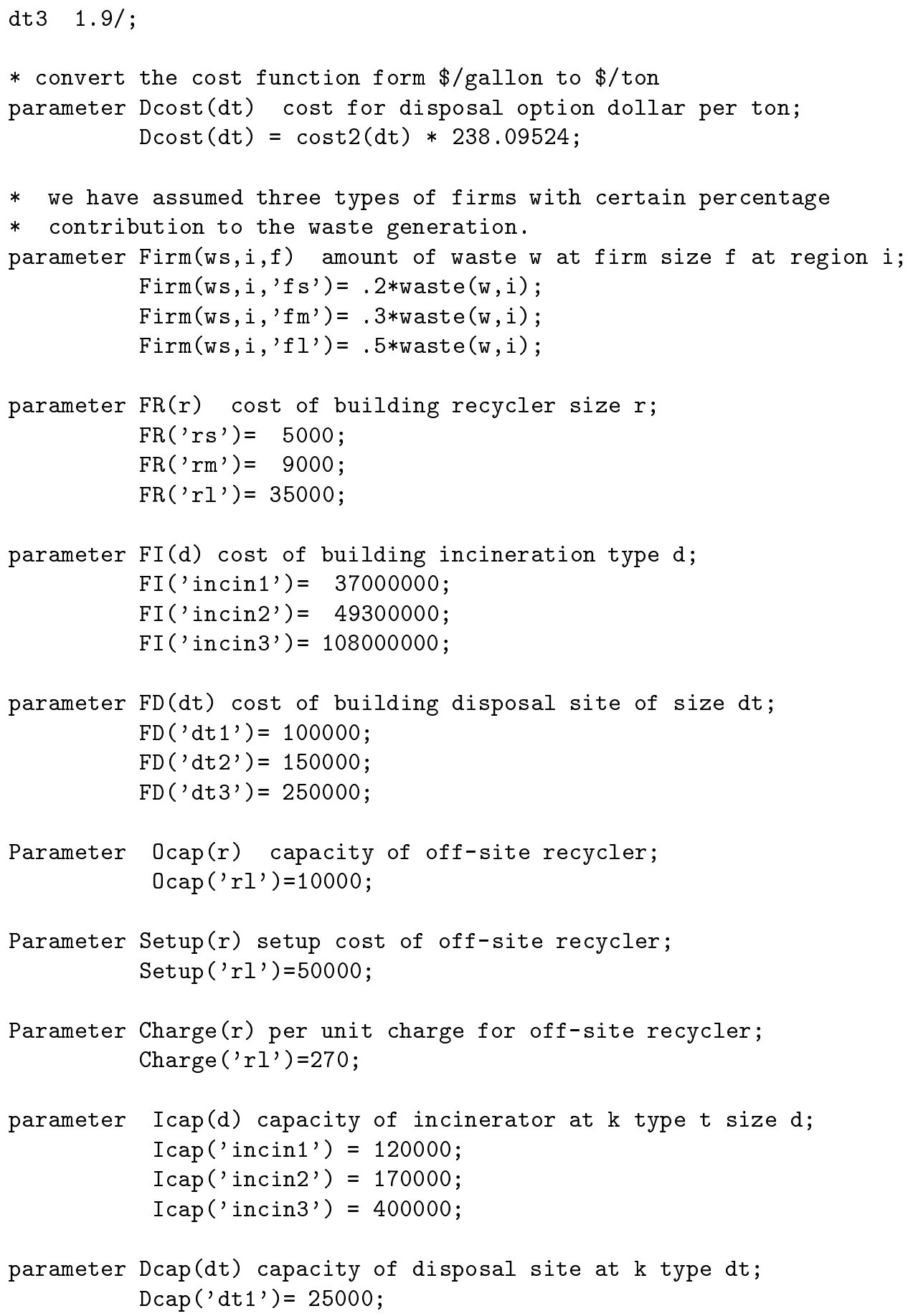




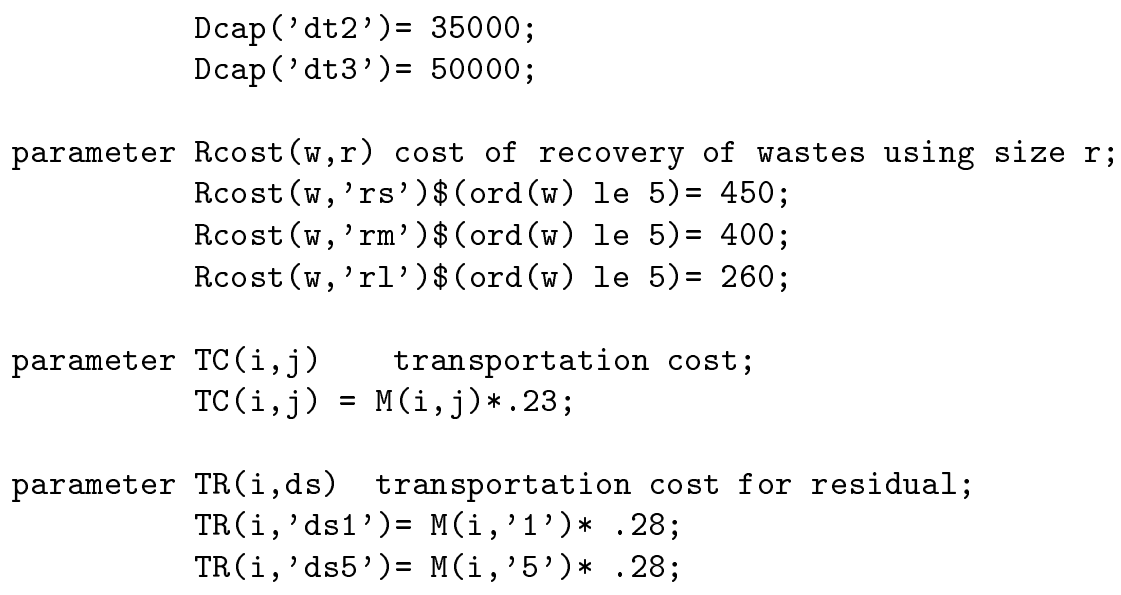




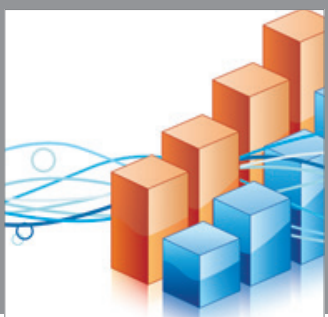

Advances in

Operations Research

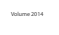

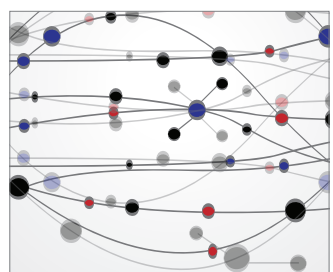

\section{The Scientific} World Journal
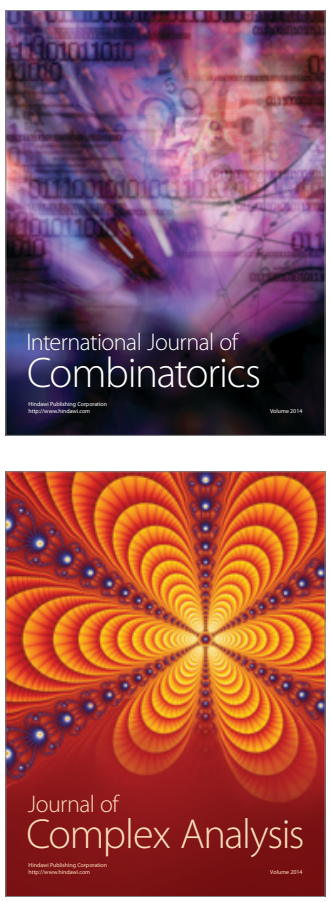

International Journal of

Mathematics and

Mathematical

Sciences
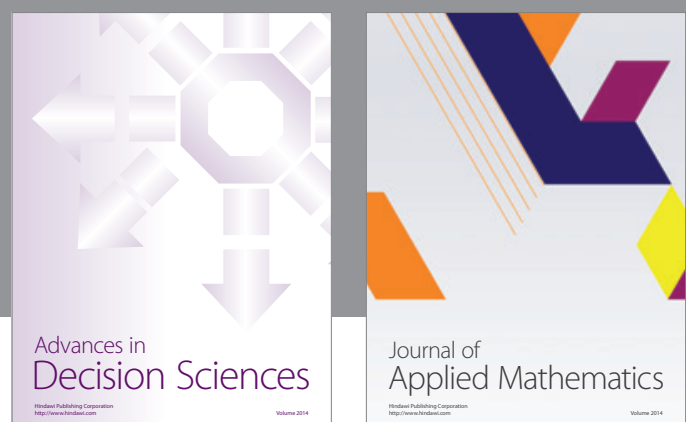

Journal of

Applied Mathematics
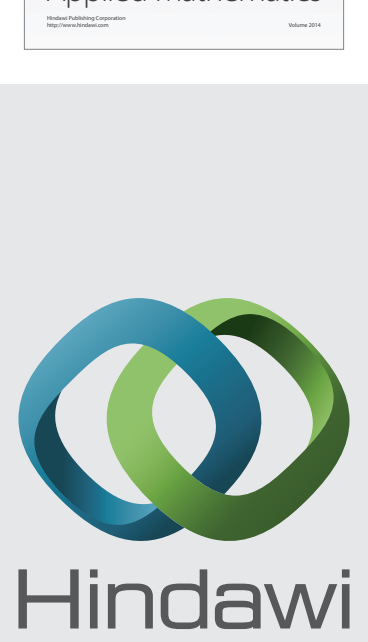

Submit your manuscripts at http://www.hindawi.com
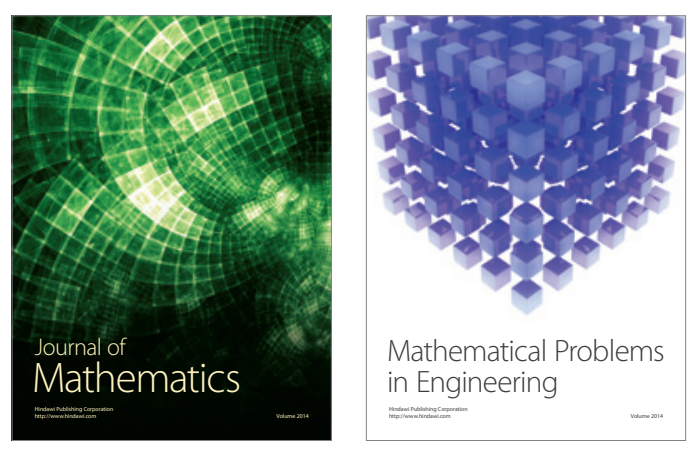

Mathematical Problems in Engineering
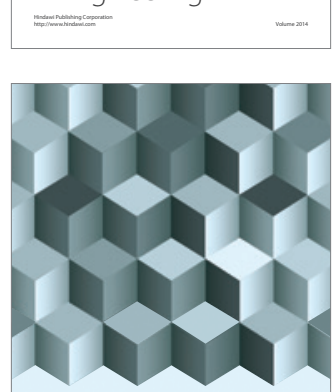

Journal of

Function Spaces
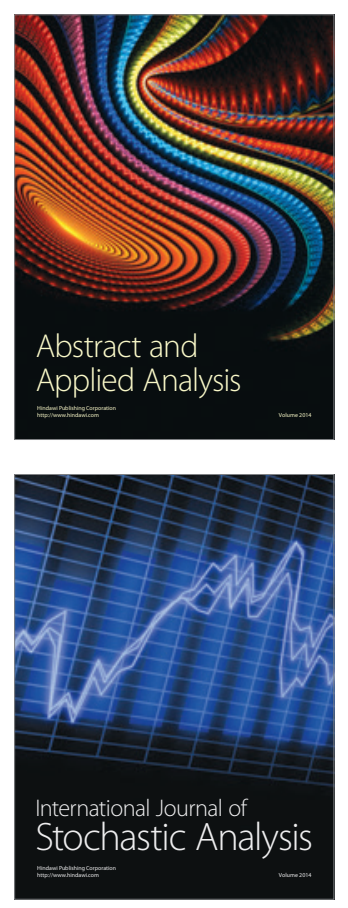

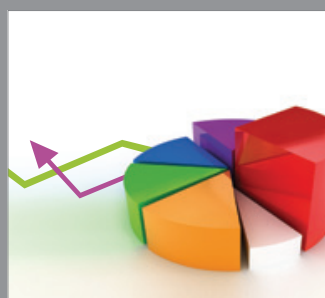

ournal of

Probability and Statistics

Promensencen
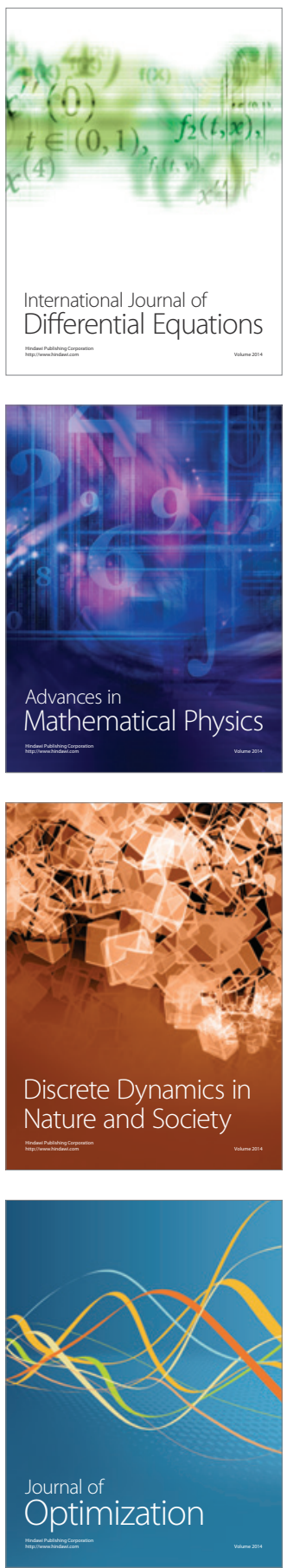